\title{
DA CRISE HUMANITÁRIA EM RAZÃO DO BLOQUEIO ECONÔMICO DOS EUA SOBRE A VENEZUELA DENUNCIADO NA OMC: UMA ANÁLISE A PARTIR DO DIREITO INTERNACIONAL PÚBLICO E DOS DIREITOS HUMANOS
}

\author{
Clara Kelliany Rodrigues de Brito ${ }^{1}$ \\ Joasey Pollyanna Andrade da Silva ${ }^{2}$ \\ Valter Moura do Carmo ${ }^{3}$
}

\begin{abstract}
Resumo: A pesquisa aborda, através do Direito Internacional Público, as questões humanitárias e socioeconômicas que a Venezuela atravessa, em decorrência dos bloqueios econômicos (embargos) promovidos pelos Estados Unidos da América perante a Organização Mundial do Comércio (OMC). Foi utilizado o método dedutivo por meio de levantamento bibliográfico em livros, revistas digitais e artigos científicos. O resultado demonstrou que os embargos desrespeitam os direitos humanos, não garantindo o mínimo necessário para a dignidade da pessoa humana, por essa razão, é imprescindível que alguns Estados Soberanos possam intervir no território venezuelano para coibir atos que violem os direitos fundamentais.
\end{abstract}

Palavras-chave: Crise Humanitária; Venezuela; Embargos.

\section{ON THE HUMANITARIAN CRISIS DUE TO THE UNITED STATES' ECONOMIC EMBARGOES ON VENEZUELA DENOUNCED TO THE WTO: AN INTERNATIONAL PUBLIC LAW AND HUMAN RIGHTS ANALYSIS}

\footnotetext{
${ }^{1}$ Mestranda em Direito pela Universidade de Marília - UNIMAR - Área de Concentração: Empreendimentos Econômicos, Desenvolvimento e Mudança Social; Mestranda em Ciências Jurídico-Políticas pela Universidade Portucalense Infante D. Henrique - UPT e Centro de Estudos Constitucionais e Gestão Pública - CECGEP; Especialista em Direito Público com Magistério Superior pela UNISEB Centro Universitário; Especialista em Direito e Processo do Trabalho pela Universidade Anhanguera-UNIDERP; Especialista em Direito Civil e Empresarial pelo IBMEC-SP; Graduada em Direito pela Faculdade do Maranhão; Advogada. Coordenadora e Professora da Pós-Graduação de Direito Municipal do Centro de Estudos Constitucionais e de Gestão Pública CECGP/SVT Faculdade.

${ }^{2}$ Mestranda em Direito pela Universidade de Marília - UNIMAR, sendo bolsista da CAPES. Graduada em Direito e em Enfermagem pela Universidade de Marília. Especialista em Gerontologia pela Universidade Estadual do Sudoeste da Bahia e em Saúde Pública pela Faculdade Internacional de Curitiba. Atuou durante 05 anos no Programa Saúde da Família na USF- Dr. Eliezer Mendes como Enfermeira contratada pela Prefeitura Municipal Lajedo do Tabocal/BA. Desempenhou a função de Docente e Supervisora de Estágio Curricular no Ensino Técnico Profissionalizante de Enfermagem pelo Colégio Politécnico Humberto Ribeiro Reis na cidade de Jequié/BA. Do mesmo modo atuou na docência como professor na Universidade Tiradentes na Cidade de Aracaju/SE e na Cidade de JequiélBA exerceu a função de Gerente Coordenadora da USF-Senhorinha Ferreira de Araújo e no ensino superior como Docente na instituição de ensino FAPEC- Faculdades Unidas de Pesquisa, Ciências e Saúde LTDA.

${ }^{3}$ Possui graduação em Direito pela Universidade de Fortaleza - UNIFOR; mestrado em Direito Constitucional pela UNIFOR com período sanduíche na Universidade Federal de Santa Catarina - UFSC e doutorado em Direito pela UFSC, tendo realizado o doutorado sanduíche na Universidade de Zaragoza (Espanha) com bolsa do PDSE da CAPES e período de investigação na Universidade Federal da Paraíba - UFPB com bolsa do PROCAD da CAPES. Realizou estágio de pós-doutorado na Universidade de Marília - UNIMAR com bolsa do PNPD da CAPES. Professor Colaborador do mestrado em Prestação Jurisdicional e Direitos Humanos da UFT em parceria com a ESMAT.
} 
Abstract: This research addresses, based on International Public Law, the humanitarian and socioeconomic questions concerning Venezuela's situation in face of the economic embargoes promoted by the United States before the World Trade Organization (WTO). The deductive method was used through bibliographic research in books, digital journals and scientific papers. The result demonstrates that the embargoes infringe upon human rights, by not guaranteeing the absolute minimum necessary to the dignity of the human person, thus, it is pivotal that some sovereign states are allowed to intervene on Venezuelan territory in order to restrain acts in defiance of fundamental rights.

Keywords: Humanitarian Crisis; Venezuela; Embargoes.

\section{INTRODUÇÃO}

O Direito Internacional Público é um ramo do Direito que trata das relações entre Estados e Organizações Internacionais, visando principalmente estabelecer a justiça e segurança entre as nações, bem como assegurar o respeito aos Direitos Humanos por meio de uma legislação voluntária e descentralizada. Porém, essa área do direito ainda encontra algumas dificuldades para atuar de forma efetiva e satisfatória, como no caso da Venezuela.

Como aconteceu no final de 2013, em decorrência da crise na Venezuela, houve uma desaceleração da economia, reduzindo postos de trabalho, acarretando, dessa forma, uma das crises econômicas que destruiu a política interna e foi marcada pelo autoritarismo e violação de diversos direitos consagrados em seu ordenamento jurídico interno e externo, violando, assim, tratados ratificados dos quais o país era signatário.

A falta de diálogo com os EUA agravou a situação econômica e política do país, levando a um verdadeiro colapso, com reflexos negativos no plano internacional. Logo, a Venezuela encontrava-se em um cenário crítico que culminou na sua suspensão do MERCOSUL e de diversos embargos internacionais, além da inconveniente ameaça de sofrer uma intervenção militar direta dos Estados Unidos, o que levou o governo de Maduro a protocolar, em 26 de março de 2021, uma denúncia contra os Estados Unidos na Organização Mundial do Comércio (OMC) pelo bloqueio econômico imposto desde 2015.

A proposta desse texto finca-se na tentativa de responder à seguinte problemática: como o Direito Internacional Público pode atuar na crise humanitária enfrentada pela Venezuela? Como o bloqueio econômico (embargos) dos EUA sobre a Venezuela, denunciado na OMC, contribuiu para a violação de direitos que garantem o patamar 
civilizatório mínimo da pessoa humana? E quais os reflexos socioeconômicos desses embargos?

Para responder a esse questionamento, foi realizado o estudo através da metodologia bibliográfica, utilizando o método dedutivo, com abordagem qualitativa. Para Olivier Corten (2009), é imprescindível compreender que a metodologia não se baseia em afirmar a existência de tal ou qual regra jurídica, ou até mesmo em requerer seus significados. Oferece, sim, ao pesquisador ferramentas no intuito de interpretar uma norma ou desenvolver e expor de forma genérica o raciocínio e conhecimento jurídico mais adequado.

Para encontrar as hipóteses relativas ao problema proposto, esse estudo se dividiu em cinco partes. A primeira parte apresenta a crise social instalada na Venezuela, as informações foram coletadas por organismos internacionais, organismos não governamentais, dados jornalísticos e materiais indexados sobre o tema.

A segunda parte demostra os aspectos inerentes aos embargos sofridos pela Venezuela e a relevância do Direito Internacional Público, bem como a situação de desabastecimento em decorrência das sanções; também se demostraram algumas transações que o país tenta para manobrar a escassez de produtos diversos.

$\mathrm{Na}$ terceira parte, a pesquisa concentrou-se em apresentar os contornos da crise humanitária e da violação de direitos à luz da dignidade humana em decorrência da atual situação do país caribenho que, em meio a tantas crises, ainda tem que atravessar pelos impactos devastadores da pandemia da Covid-19.

$\mathrm{E}$, finalmente, teceram-se considerações finais divididas em duas partes: a primeira avaliou os aspectos econômicos; e a parte final avaliou as questões humanitárias, além de trazer importantes ponderações sobre a problemática proposta pelo estudo feito.

\section{DA CRISE NA VENEZUELA E SEUS APECTOS SOCIAIS}

Para entender a crise na Venezuela, é necessário reportar-se a uma série de informações geopolíticas do país cujos governos, desde o começo do século passado, bem antes da Grande Crise de 1929, deixaram a agricultura e a indústria em um segundo plano para focar somente em petróleo, que recentemente respondeu por $96 \%$ das exportações, em uma dependência quase plena (CORAZZA; MESQUITA, 2018). 
Em 2016, o PIB do país atingiu pouco mais de US\$ 287 bilhões, e era o quarto PIB da América Latina, do qual 25\% são representados pelo setor de óleo e gás, sendo considerada, de longe, a maior reserva de petróleo no mundo, composta aproximadamente por um pouco mais 300 (trezentos) bilhões de barris, o que corresponde a cerca de 17,5\% de todo petróleo do planeta, enquanto as de gás natural somam quase 6 (seis) trilhões de metros cúbicos, o que faz da Venezuela a maior reserva não só de petróleo, mas também de hidrocarbonetos do mundo, com o seu auge de produção entre os anos de 2014 e 2015 (BRASIL, 2019).

A Venezuela localiza-se em um área geográfica privilegiada, com seu petróleo conseguindo chegar mais rápido ao maior consumidor do mundo, os Estados Unidos, levando uma média de cinco dias para entregá-lo aos compradores americanos, uma vantagem bem superior ao óleo do Oriente Médio, que leva cerca de quarenta dias para entregá-lo. Considerando todas essas vantagens, o Presidente Juan Gómez, que governou em ditadura entre os anos de 1908 a 1935, passou a explorar tais reservas e desenvolver relações econômicas privilegiadas com os EUA (BORGES, 2021).

Os frutos dessa relação comercial possibilitaram à Venezuela um salto em condições de desenvolvimento e infraestrutura no país, principalmente portuárias. Recebendo, por volta de 1950, o status do segundo maior produtor de petróleo, sendo o primeiro exportador mundial da substância (maior que qualquer país árabe). Entretanto, esse status econômico dependia única e exclusivamente do seu maior cliente, os EUA (DELGADO; STIER; FEBRARO; MARQUES, 2017).

Por outro lado, é preciso destacar que, mesmo diante da sua produtividade e estrutura econômica, a Venezuela não conseguia resolver seus problemas e as grandes diferenças sociais internas, o que resultava num regime democrático instável. O milagre venezuelano não iria durar para sempre, e o preço por não ter investido o suficiente em educação e tecnologia para a indústria de base seria cobrado, mais cedo ou mais tarde.

De acordo com a Organização Mundial do Comércio (OMC), o petróleo corresponde a 96\% do total das exportações do país (OMC, 2002), o que explica a crise petrolífera no ano de 2014, em que o valor do petróleo cai vertiginosamente em decorrência da crise gerada pela recusa de Irã e Arábia Saudita assinarem um compromisso para reduzir a produção ${ }^{4}$ em um

\footnotetext{
${ }^{4}$ No início de 2014, depois de ter alcançado um pico de US\$138,54 em 2008, o preço do barril de petróleo era negociado a cerca de US\$ 100 dólares e caiu pela metade no fim do ano, mantendo essa queda significativa até este ano, quando voltou a atingir o patamar de US\$ 80.
} 


\section{DA CRISE HUMANITÁRIA EM RAZÃO DO BLOQUEIO ECONÔMICO DOS EUA SOBRE A VENEZUELA DENUNCIADO NA OMC: UMA ANÁLISE A PARTIR DO DIREITO INTERNACIONAL PÚBLICO E DOS DIREITOS HUMANOS}

momento de redução da demanda, além de outros fatores, como a "desaceleração da economia chinesa e o crescimento, nos EUA, do mercado de produção de óleo e gás pelo método fracking - o faturamento hidráulico de rochas de xisto betuminoso, na região de Pittsburg, Pensilvânia.” (CORAZZA; MESQUITA, 2018. p. 1).

Assim, além de faturar menos por seu principal produto, o país ainda teve uma queda expressiva na produção ${ }^{5}$, praticamente tendo deixado de produzir, pois já atingira a média de 100 mil barris por dia. Tudo isso também teria o seu preço a pagar, pois o governo não investiu nem em agricultura e tecnologia, nem na indústria do petróleo, o que acarretou na queda da produção de barris (BRASIL, 2020) e em uma série de medidas que acabaram emperrando o crescimento e desenvolvimento da indústria local, tais como a nacionalização das indústrias petrolíferas multinacionais, das indústrias de cimento e aço, entre outras, e expropriou diversas empresas e propriedades rurais, fazendo o mercado interno substituir tudo pelas importações mais baratas, até então subsidiadas pelo governo. (CORAZZA; MESQUITA, 2018).

Porém, houve investimentos em programas sociais com o intuito de solucionar os problemas enraizados na Venezuela com a ascensão do chavismo, reduzindo, assim, a desigualdade social, que, segundo o índice $\mathrm{GINI}^{6}$, era de $54 \%$ a pobreza, caindo para $7,6 \%$ em 2010, mas com um avanço tremendo na saúde pública, diminuindo significativamente a mortalidade infantil, aumentando o acesso à saúde para a população, com a média de dezoito médicos para cada dez mil habitantes. Esses programas sociais beneficiaram mais de vinte milhões de pessoas, gerando bem-estar social, o que colocou o país como o de menor desigualdade entre ricos e pobres na América Latina em 2012, existindo uma verdadeira adoração ao chavismo (BENEDITO, 2016).

\footnotetext{
${ }^{5}$ Comparando a quando Chávez assumiu pela primeira vez o país, em 1999, quando a produção era de mais de 3 milhões de barris por dia, atualmente é de 100.000 a 200.000 barris por dia e está caindo. Para se ter uma ideia da situação, essa produção era de cerca de 650.000 barris por dia há apenas um ano, e tinha chegado a 2 milhões de barris em 2017, quando passou a cerca de 1 milhão em 2018 e foi caindo. Agora é concebível que o país possa em breve estar produzindo zero barris, ou muito perto disso (BRASIL, 2020).

6 "O Índice de GINI, criado pelo matemático italiano Conrado Gini, é um instrumento para medir o grau de concentração de renda em determinado grupo. Ele aponta a diferença entre os rendimentos dos mais pobres e dos mais ricos. Numericamente, varia de zero a um (alguns apresentam de zero a cem). $\mathrm{O}$ valor zero representa a situação de igualdade, ou seja, todos têm a mesma renda. O valor um (ou cem) está no extremo oposto, isto é, uma só pessoa detém toda a riqueza. Na prática, o Índice de Gini costuma comparar os $20 \%$ mais pobres com os $20 \%$ mais ricos" (WOLFFENBÜTTEL, 2004).
} 
Ao adotar uma política equivocada de controle de preços, o governo gerou a inflação, que culminou no sucateamento da indústria nacional, passando a depender de importações, seja de alimentos, produtos de higiene, medicamentos, até pneus e peças de manutenção para o sistema de metrô das grandes cidades, além de ter implantado uma política cambial equivocada para segurar o valor do bolívar, a moeda do país, controlando a aquisição de dólares pela população, o que motivou o surgimento do mercado paralelo da venda da moeda americana. (CORAZZA; MESQUITA, 2018).

Devido à queda internacional do preço do barril de petróleo que desarticulou a economia venezuelana, além de escândalos de corrupção, foi a causa da crise no setor, que através de investigações realizadas pelo Departamento de Justiça dos EUA demonstrou um esquema de lavagem de dinheiro da estatal Petróleos de Venezuela (PDVSA), que teria desviado uma verba de US\$ 1,2 bilhão nos anos de 2014 e 2015 na operação Fuga de Dinheiro. Em 2017, a justiça decretou a prisão de nove diretores e processou 90 exempregados da petroleira, acusados de envolvimento em esquema de corrupção (CORAZZA; MESQUITA, 2018).

Com as dificuldades nas exportações petrolíferas e sem produção agrícola e industrial, houve uma desvalorização da moeda, acarretando uma hiperinflação. Com o intuito de melhorar o cenário econômico, Chávez implementou medidas para o controle artificial da inflação, obrigando os produtores a venderem os produtos a preços abaixo do custo, o que ocasionou a falência de diversas indústrias e comerciantes. À vista disso, houve um aumento na taxa de desemprego e elevação no índice de pobreza, que chegou a 87\% em 2017 (ESPAÑA N.; PONCE Z., 2018).

A escassez de recursos pelo governo, a mitigação da moeda circulando pelo país, que impede que as empresas produzam, trouxe uma grande crise humanitária na Venezuela, que, de acordo o relatório Human Rights Watch (2019), sendo as últimas informações publicadas em 2017 pelo Ministério da Saúde, apontaram um aumento no índice da mortalidade materna de 65\%; na mortalidade infantil de 30\%; no quadro de desnutrição moderada ou grave em menores de cinco anos aumentou de $10 \%$ para $17 \%$ em 12 meses; e nos casos de malária elevou o índice para 76\% (HUMAN RIGHTS WATCH, 2019). 


\title{
3. OS EMBARgOS ECONÔMICOS E O AGRAVAMENTO DA CRISE NA VENEZUELA E A RELEVÂNCIA DO DIREITO INTERNACIONAL PÚBLICO
}

O Direito Internacional Público, conforme Francisco Rezek, possui um caráter voluntário e descentralizado. Isso significa que as normas utilizadas são aplicáveis aos países que concordem com a sua adoção, inexistindo um Estado Soberano com mais poder do que outros. São firmados tratados, ou seja, acordos formais, os quais são pactuados e executados por pessoas jurídicas de Direito Internacional Público, quer sejam Estados Soberanos e organizações internacionais com o objetivo de obter efeitos jurídicos que regulamentam a sociedade internacional (REZEK, 2018). O Direito Internacional Público possui uma grande relevância, pois regula e atua de forma harmônica na sociedade internacional, buscando soluções mais humanitárias, preservando a dignidade da pessoa humana (REZEK, 2018).

A situação na Venezuela é crítica, e de todos os problemas apresentados e circunstâncias internas decorrentes desse país, sem dúvida a mais impactante é a crise comercial e humanitária que a Venezuela vive, decorrente dos embargos comerciais e do bloqueio econômico norte-americano, a população sofre com pouca água potável, insalubridade das ruas e cidades, escassez de alimentos e recursos gerados, falta de emprego e baixo poder aquisitivo. Dessa maneira, torna-se evidente o descaso da Venezuela a princípios basilares defendidos pelo Direito Internacional Público, como a dignidade da pessoa humana, e o mínimo existencial para a sobrevivência humana. Assim alude André Regis (2006, p. 10):

\begin{abstract}
Os defensores das Intervenções Humanitárias passaram a argumentar que, de acordo com a própria Carta das Nações Unidas, qualquer regime que provoque fome ou genocídio, como nos casos da Somália ou Ruanda, é uma ameaça à paz mundial. E, caso a ideia de soberania esteja sendo usada para proteger regimes sanguinários, ela não deve ser aplicada. Assim, para eles, fome e genocídio não devem ser considerados assuntos exclusivos de determinadas populações circunscritas a um território. São assuntos de todos.
\end{abstract}

Durante o seu mandato governamental, Barack Obama editou a Lei 113/278 (Lei Pública de Defesa dos Direitos Humanos e da Sociedade Civil), aprovada pelo Congresso Americano. Essa norma americana tenta "justificar as ações de bloqueio, com base em juízos de valor sobre a situação econômica venezuelana, particularmente no que diz respeito ao acesso a alimentos, medicamentos e outros produtos básicos” (WEISSHEIMER, 2019, p. 1). 
Porém, paradoxalmente, ao invés de resolver tais problemas, os agravou, sendo responsável pelo desabastecimento e pela hiperinflação na economia local, uma vez que os EUA proibiram qualquer instituição financeira que tenha sede em seu território de fazer qualquer transação com o país latino, ou ainda, com alguma pessoa ou com uma empresa venezuelana. (SEM BLOQUEIO..., 2019)

E os citados embargos não são apenas para os bancos, mas, sim, agem também nas empresas de logística e transporte de mercadorias, o que inclui até as transportadoras de alimentos que chegam à Venezuela, pois os EUA têm monitorado todas as embarcações que atracam nos portos venezuelanos, piorando a situação ao atracar nos portos venezuelanos, uma vez que ficam proibidos de chegarem na Europa (EUA APREENDEM..., 2020).

Por essa razão, a Venezuela não pode mais receber peças ou qualquer tecnologia industrial, principalmente no que se refere à indústria petrolífera, que perdeu sua capacidade de refino, e perde cada vez mais a de exploração. É por isso que a solução para que o país possa receber combustível e algum alimento ou medicamento tem sido a importação desses produtos por meio do Irã e de outros países que se encontram em situação de semelhante antagonismo em relação aos americanos, clandestinamente (sem registro ou bandeira de navegação e negado pelas autoridades oficiais do país persa), de onde tem vindo o combustível, e mesmo assim, tem sido alvo de pilhagem e confisco por parte dos EUA. É tanto que, em um episódio recente, os EUA chegaram a faturar mais de 40 milhões de dólares com um leilão que fez do combustível apreendido em quatro navios iranianos que seguiam com destino à Venezuela. (EUA FATURA..., 2020).

Mas, embora sob o risco de pilhagens e confiscos, ou até de outras retaliações mais violentas, as operações clandestinas com navios iranianos continuam acontecendo, pois não há outra saída para a Venezuela neste momento, a não ser contar com os opositores ao governo americano, usando a velha prática do "o inimigo do meu inimigo é meu amigo".

Essa é a realidade da relação entre esses dois países, no momento. Ademais, as companhias de transporte naval não querem mais transportar produtos para a Venezuela, porque serão penalizadas, ou seja, proibidas de atracarem nos Estados Unidos e na Europa (SEM BLOQUEIO..., 2019). Isso agrava o desabastecimento do país e a população não tem mais nem como se alimentar, não tem mais acesso a medicamentos, desde os mais básicos até os que tratam de doenças como AIDS e Câncer. 


\section{DA CRISE HUMANITÁRIA EM RAZÃO DO BLOQUEIO ECONÔMICO DOS EUA SOBRE A VENEZUELA DENUNCIADO NA OMC: UMA ANÁLISE A PARTIR DO DIREITO INTERNACIONAL PÚBLICO E DOS DIREITOS HUMANOS}

Só em 2018, a insuficiência de alimentos e de medicamentos compeliu 2,3 milhões de venezuelanos a abandonarem seus lares e deixarem o país, segundo a ONU, que emitiu um alerta para o risco de dezenas de milhares de cidadãos deixem a Venezuela, de onde já emigraram mais de 5 milhões de pessoas (GLOBAL NEWS, 2018).

Alena Douhan, relatora especial da ONU, manifestou-se pelo fim das medidas impostas pelos embargos, em fevereiro de 2021, pedindo o fim da conduta repressiva dos EUA, União Europeia e outros países em face da Venezuela, apresentando um relatório avaliativo minucioso sobre sua visita de duas semanas ao país. "As sanções exacerbaram a situação econômica e humanitária pré-existente [...], que teve um efeito devastador sobre toda a população venezuelana, especialmente aqueles em extrema pobreza" (ESPECIALISTA DA ONU..., 2021).

É imprescindível que a Soberania nacional seja um alicerce essencial para constituir um Estado soberano, no entanto, a sociedade internacional não deve se submeter e nem concordar com medidas que resultem em violação de direitos humanos, desrespeitando indivíduos venezuelanos, pois são seres humanos e devem ter os seus direitos assegurados e protegidos por lei.

\section{DA CRISE HUMANITÁRIA E DA VIOLAÇÃO DE DIREITOS À LUZ DA DIGNIDADE HUMANA}

Como relatado nos tópicos anteriores, a situação da Venezuela é complexa e caótica, pois, com a morte de Chávez, estima-se que o país perdeu cerca de US\$22 bilhões em investimentos anuais. As políticas impostas pelos EUA para combater o regime do então Presidente Nicolas Maduro possuem reflexos humanitários preocupantes que violam o patamar mínimo civilizatório do indivíduo (CORPI, 2019).

Segundo o Centro Estratégico Latino-americano de Geopolítica - Celag:

Entre 2013 e 2017, os embargos americanos, de acordo com um estudo do Centro Estratégico Latino-Americano de Geopolítica (CELAG), causaram um prejuízo de US\$ 350 bilhões à Venezuela, além do fechamento de 3 milhões de postos de trabalho. Esse número corresponde a $24 \%$ da população ativa do país. As sanções impostas pelos Estados Unidos não são um embargo comercial completo, como foi o caso de Cuba. Afinal, foram impostas principalmente em funcionários do governo e indústrias-chave, como petróleo e gás, ouro e finanças. Em 2017, novas sanções compulsórias 
bloquearam também medicamentos e alimentos. Isso afetou diretamente a economia do país, uma vez que ele depende da importação de diversos produtos. (CELAG, 2019).

Essas novas sanções deram ensejo à maior crise migratória sofrida pela América Latina, denominada de "êxodo venezuelano"7, pois, com os embargos, a população ficou privada da compra de produtos de primeira necessidade e de remédios.

A insistência em continuar com os embargos vem aumentando o conflito entre o Governo de Nicolás Maduro e o presidente da Assembleia Nacional, Juan Guaidó, reconhecido como "presidente interino" por mais de cinquenta países. Diante de tal situação, o problema que já era evidente ganhou maiores proporções com a pandemia da Covid-19.

Em meio à crise política, temos milhares de cidadãos venezuelanos vivendo abaixo da linha da pobreza extrema, ou seja, 79\% da população, sem garantia de qualquer direito e completamente vulneráveis perante um Estado desestruturado sem a mínima condição de garantir direitos mínimos. É importante ressaltar que a Venezuela nunca havia chegado a números tão elevados de pobreza datados do séc. XX e XXI, segundo os dados apresentados pelo professor Luís Pedro España, pesquisador da Universidade Católica Andrés Bello, que lidera o estudo sobre a situação de extrema pobreza que o país atravessa (SINGER, 2020).

Tais números nos levam a sérias reflexões sobre até que ponto os embargos comerciais podem ser vistos como mecanismo ideal de solução de conflitos comerciais, ou, ainda, qual limite os embargos podem alcançar, pois diante dos dados absurdos aqui apresentados, são abertos um leque de demandas que clamam por medidas urgentes. A situação demostra completa violação de direitos humanos, que, no conceito de Carlos Soares Nino (1991 apud PIOVESAN, 2011, p. 36), consiste em: “direitos humanos são uma construção consciente vocacionada a assegurar a dignidade humana e a evitar sofrimento, em face da persistente brutalidade humana".

Luigi Ferrajoli (2002, p. 338) traz a seguinte definição que "direitos humanos simbolizam a lei do mais fraco contra a lei do mais forte, na expansão de 'contrapoder' em face dos absolutismos, advindos do Estado, do setor privado ou mesmo da esfera doméstica".

Assim, é possível constatar que, por mais variadas que sejam as definições de direitos humanos, todas possuem um ponto em comum, que é o fato de representarem valores

\footnotetext{
${ }^{7}$ Denominação dada ao movimento migratório em massa da população venezuelana a caminho do Brasil e Peru na tentativa de conseguir melhores condições de vida que garantam o mínimo existencial (CORPI, 2019).
} 
essenciais na proteção e promoção da dignidade humana, os valores essenciais para uma vida digna. Nesse sentido, é importante destacar que:

A conceituação de dignidade humana é comumente tratada pelos pensadores modernos e contemporâneos, dentre eles um dos maiores interlocutores de Hegel, Kant, como sendo derivada da capacidade humana de agir e pensar racionalmente, centralizando toda a discussão sobre a dignidade humana no respeito à autonomia do sujeito racional.

Nesta afirmação, nota-se a identificação entre dignidade e capacidade de ação racional, o que acompanha todo o caminho do pensamento ocidental sobre esse conceito.

Hegel, introduzindo a história em sua compreensão de dignidade humana, entende que a dignidade constrói-se e realiza-se mediante a relação com o outro. Enquanto para Kant o respeito à autonomia de um pode resultar na limitação dos demais, caracterizando uma valorização do individual, para Hegel, o reconhecimento de um outro igualmente digno somente pode-se compreender mediante a consideração de uma coletividade construída no âmbito das relações.

Sob o prisma meramente ontológico, ou religioso, a dignidade não serve de parâmetro para demarcar concretamente as questões éticas atuais que envolvem a vida humana. Ela necessita ser descentralizada do indivíduo e colocada na base das relações e no desenvolvimento histórico humano. (ALMEIDA, 2014, p. 377).

Portanto, sobre a dignidade humana se faz necessário compreender os ensinamentos de Hegel, que afirma que ideia de dignidade humana é considerada com base em um conceito maduro, resultado de um complexo processo de reconhecimento, que ocorre por meio da luta e da conquista na tentativa de modificar e aprimorar o conceito de dignidade humana (HEGEL, 2001).

É a partir dessa premissa que o direito passa a traçar e reconhecer os preceitos inerentes à dignidade humana. Essa redescoberta vem acompanhada de alguns documentos internacionais, como o Estatuto das Nações Unidas, a Declaração Universal dos Direitos Humanos, e tantos outros documentos oriundos dos países signatários da ONU, como a Constituição Brasileira de 1988 e a Constitución de la República Bolivariana de Venezuela (1999). Esta última traz que:

[...] la organización jurídico-política que adopta la Nación como un Estado democrático y social de Derecho y de Justicia. El Estado propugna el bienestar de los venezolanos, creando las condiciones necesarias para su desarrollo social y espiritual, y procurando la igualdad de oportunidades para que todos los ciudadanos puedan desarrollar libremente su personalidad, dirigir su destino, disfrutar los derechos humanos, y buscar su felicidad. 
Vale destacar que a lei base da República da Alemanha é um exemplo mundial devido ao horror vivido durante a Guerra Mundial, especialmente durante a Segunda Guerra Mundial (FERNANDES, 2020).

Nessa esteira, o Direito Alemão se tornou referência nos ensinamentos dos direitos humanos, conectando a ele valores de igualdade independentemente de raça, religião, sexo, opiniões políticas, entre outros que se assemelhem aos pregados pela Alemanha Nazista. Sendo assim, ele possui característica de conceito aberto arreigado de valores sociais (MORAES, 2019).

Já para a doutrina italiana, a dignidade não é tão intangível, não se atribui o adjetivo "pessoa", mas sim "dignidade social". Portanto, o conceito de dignidade defendido pelos italianos está relacionado ao preconceito econômico e social, é inerente ao trabalho e é um meio necessário para tornar as pessoas dignas. Portanto, o desejo aqui não acontece por causa da própria pessoa, como na doutrina alemã, mas é um processo que ajuda o indivíduo a se integrar à sociedade. Porque foi a partir dessa inserção que assumiu o direito e a obrigação de colaborar com o desenvolvimento social através do seu trabalho (FERNANDES, 2020).

Entretanto, mesmo diante de tais ponderações, muitos autores acastelam a dificuldade de conceituar a dignidade humana, utilizando como ponto de partida as noções trazidas pela doutrina constitucionalista dominante, mesmo que sobre ela pesem algumas críticas. Assim, conforme a corrente dominante, a dignidade da pessoa humana é construída como metaprincípio, radiando valores que devem ser adicionados para interpretação dos demais diretos fundamentais e determinando que qualquer indivíduo receba tratamento igualitário, "sempre tratando cada pessoa como o fim em si mesmo e nunca como meio para satisfazer outros interesses" (FERNANDES, 2020 p. 351).

Além disso, os estudiosos constitucionais atuais consideram os direitos à vida, liberdade, igualdade e propriedade como motivos razoáveis para a assunção da dignidade humana, pois a dignidade é um super princípio dotado de valor, e é mais importante do que qualquer outro princípio em termos de hierarquia. Em outras palavras, é parte integrante da ligação entre a moralidade e o direito. Sob esse ponto de vista, portanto, o Direito está enraizado na moralidade e encontra o seu fundamento e justificação na racionalidade (HABERMAS, 2002). 


\section{DA CRISE HUMANITÁRIA EM RAZÃO DO BLOQUEIO ECONÔMICO DOS EUA SOBRE A VENEZUELA DENUNCIADO NA OMC: UMA ANÁLISE A PARTIR DO DIREITO INTERNACIONAL PÚBLICO E DOS DIREITOS HUMANOS}

Assim, é preciso notar que, apesar dos esforços doutrinários para esquematizar, o conceito de dignidade humana não chegou ainda ao modelo ideal. Contudo, há de se observar a aplicação criteriosa de parâmetros mínimos para que se possa conseguir alcançar as dimensões ou valores na consecução normativa da dignidade para que o indivíduo não seja instrumentalizado (BARROSO, 2013).

A doutrina estabelece quatro dimensões que servem de parâmetro para auferir a defesa normativa de dignidade humana. A primeira dimensão consiste na não instrumentalização que consiste na afirmação de que o ser humano não pode ser "coisificado", ou seja, nunca deve ser tratado como meio para se conseguir determinado fim. Tal premissa é inspirada em Kant, que defende que "o ser humano deve ser o fim em si mesmo, não só como meio" (KANT, 2007, p. $68)$.

A segunda dimensão seria a autonomia existencial, que consiste na garantia da liberdade existencial, ou seja, cada pessoa tem o direito de fazer escolhas para sua vida e agir conforme suas escolhas, desde que não transgrida a lei ou afete terceiros de modo a prejudicar (FERNANDES, 2020).

A terceira dimensão consiste no direito ao mínimo existencial, sendo a mais importante, pois é sobre a ausência dela no cenário venezuelano que esse estudo traz como violação de direitos. Tal dimensão se finca no constitucionalismo social, que defende que existam condições mínimas para que se possa garantir a vida. Esse patamar mínimo civilizatório acaba sendo não só pressuposto da vida em si, mas para uma vida digna com condições para exercer as liberdades privadas, uma autonomia existencial, e liberdades públicas que consistem nos direitos políticos. Vale destacar que, como são direitos que garantem o mínimo existencial para que se possa exercer os direitos inerentes à cidadania, eles não são atrelados ao princípio da reserva do possível, por serem direitos inerentes a qualquer pessoa (BRANCO; MENDES, 2020).

Por fim, a quarta dimensão, denominada de direito ao reconhecimento, parte da ideia de que a injustiça pode ocorrer não apenas no âmbito da redistribuição de bens, mas também no âmbito do reconhecimento. Este conceito visa mostrar que, mesmo que a outra parte seja diferente, ela deve reconhecer a outra parte e nunca menosprezar seus valores, como a honra e a dignidade de raça, etnia ou grupos religiosos (FERNANDES, 2020). 
Tais dimensões funcionam como parâmetros de aferição do sentido e conceito da dignidade humana. O fato é que, perante os números apresentados pelos estudos apontados no decorrer deste trabalho, mostra-se o quão necessário e urgente é uma resposta da $\mathrm{OMC}$, que foi criada em $1^{\circ}$ de janeiro de 1995 , sendo um dos resultados mais importantes do GATT (General Agreement on Trande and Tarifs), tendo como objetivo principal o aumento dos níveis de vida, a expansão do comércio e da produção de bens e serviços, o pleno emprego, a proteção do meio ambiente, a sustentabilidade e o empenho para garantir uma maior participação de forma mais efetiva dos países em crescimento no comércio internacional. Sendo assim, é importante destacar que o papel da OMC é de suma importância para o cenário mundial, porém, conforme a própria declaração institucional feita pela organização (em seu website, na aba “quem nós somos”), traz as seguintes explicações:

[...] Em seu cerne estão os acordos da O.M.C, negociados e assinados pela maior parte das nações comerciais do mundo. Esses documentos fornecem as regras legais básicas para o comércio internacional. Eles são essencialmente contratos, obrigando os governos a manter suas políticas comerciais dentro dos limites acordados. Embora negociada e assinada por governos, a meta é ajudar produtores de bens e serviços, exportadores e importadores a conduzir seus negócios, ao mesmo tempo que permite que os governos cumpram seus objetivos sociais e ambientais.

O objetivo primordial do sistema é ajudar o fluxo comercial da forma mais livre possível - desde que não haja efeitos colaterais indesejáveis porque isso é importante para o desenvolvimento econômico e o bemestar. Em parte, isso significa remover obstáculos. Também significa garantir que indivíduos, empresas e governos saibam quais são as regras de comércio em todo o mundo. (OMC, 2021, grifo nosso).

Ante tal afirmação, podemos concluir que a própria O.M.C admite que suas medidas coercitivas não podem, de forma alguma, gerar efeitos colaterais indesejáveis; logo, as últimas medidas adotadas em 2017 afetam o bem-estar social e violam direitos básicos inerentes à dignidade humana, a não flexibilização dos embargos, afeta todas as premissas de direitos defendidas pelas Nações Unidas.

Ademais, é importante lembrar que os direitos humanos gozam de superioridade aos demais direitos, pois é do exercício dele que emanam os demais direitos/obrigações. Assim, podemos compartilhar a conclusão feita por André de Carvalho Ramos, que ensina que “direitos humanos constituem núcleo essencial de normas que compõem o ordenamento jurídico internacional contemporâneo, e então, a norma de direitos humanos é norma 


\section{DA CRISE HUMANITÁRIA EM RAZÃO DO BLOQUEIO ECONÔMICO DOS EUA SOBRE A VENEZUELA DENUNCIADO NA OMC: UMA ANÁLISE A PARTIR DO DIREITO INTERNACIONAL PÚBLICO E DOS DIREITOS HUMANOS}

hierarquicamente superior no ordenamento, seja pelo critério material ou pelo critério formal" (RAMOS, 2014, p. 167).

Por mais complexa que seja a situação da Venezuela, que se tornou um dilema internacional sobre a possibilidade de intervenção militar ou não por haver muitos pontos a serem considerados, a comunidade internacional deve se ater às condições humanitárias que o país atravessa, passando pelo retrocesso de direitos.

Vale destacar que tal condição viola a proibição ao retrocesso que macula a dignidade humana. A doutrina costuma denominar tal proteção de entrenchment (ou entrincheiramento), “expressando a necessidade de preservação do mínimo já concretizado dos direitos fundamentais/humanos, impedindo o retrocesso, que poderia ser realizado pela supressão normativa, ou, ainda, pelo amesquinhamento ou diminuição de suas prestações à coletividade" (RAMOS, 2014, p. 96).

Ademais, a insistência da OMC em permanecer com embargos da forma que se encontra, além de agravar ainda mais a situação no país caribenho, é um problema para os países da América do Sul, que, além de possuírem seus problemas socioeconômicos, precisam acolher esses povos tão castigados e massacrados pela crise que se instalou no seu país de origem. Hoje, o Brasil e o Peru são os principais destinos da migração venezuelana; além deles, a Argentina, Bolívia, Uruguai, México e países com línguas semelhantes. Porém, o Brasil e o Peru, pela proximidade, são os mais procurados (SINGER, 2020).

Vale ressaltar que o principal desafio para os países de acolhida é de como administrar tal situação de migração no momento em que as economias dos países latinos estão desaceleradas, com altíssimos déficits ficais consideravelmente piorados em decorrência da pandemia da Covid-19. No Brasil, a situação se apresenta mais delicada ainda, pois o país não consegue absorver a mão de obra dos migrantes venezuelanos no mercado interno. Há muita burocracia para que se possa legalizá-los e para validar os diplomas profissionais dos venezuelanos já regulares. Contudo, há outros aspectos importantes a serem considerados:

No plano multilateral, devem ser consideradas medidas de cooperação internacional para auxiliar os principais países receptores de migrantes venezuelanos a cobrir os custos da assistência prestada. As medidas adotadas em cada país para lidar com os imigrantes, como a imposição de restrições na fronteira, podem dificultar a ação de outros parceiros, o que indica a necessidade de uma abordagem de âmbito mais regional. 
A médio e longo prazo, assegurar o acesso à educação e aos cuidados de saúde será fundamental para que os imigrantes tenham uma vida longa e produtiva, não apenas em benefício próprio mas também das economias em que residem. (CORUGEDO; GUAJARDO, 2019, p. 2).

Diante de tantos problemas expostos sobre a atual situação humanitária que assola não só a Venezuela, mas também a América Latina, há um desejo comunitário internacional pela solução das mazelas que o país atravessa e para que sejam flexibilizados os embargos para que o país possa receber alimento, medicamento e produtos de higiene básica, para que esse povo consiga ao menos desfrutar de direitos tão básicos e necessários para vida.

\section{CONSIDERAÇÕES FINAIS}

Como é de se notar, os problemas atuais da Venezuela estão ligados a uma realidade altamente complexa, cujas explicações são várias, e ainda seguem, tentadas ao sabor das visões ideológicas, mas cuja trajetória não se iniciou, historicamente, com o Presidente Chávez nem com a sua Venezuela "bolivariana".

Para tecer as considerações finais sobre a temática proposta pelo presente trabalho, elas serão divididas em dois momentos, abordando-se os reflexos econômicos da atual situação venezuelana, e em seguida passando-se para os aspectos humanitários decorrentes do problema.

Assim, no cenário econômico, atualmente, desconsiderando os perversos efeitos da pandemia, é claro, a questão venezuelana é o maior desafio para o restante de toda a América do Sul, ou de toda a América Latina, que, na atualidade, carece do protagonismo outrora desempenhado pelo Brasil, cujos princípios de não intervenção e de não indiferença se complementaram harmonicamente, nos moldes do art. $4^{\circ}$ da Constituição Federal de 1988, mantendo um comércio mínimo necessário com o país, evitando conflitos e também uma escalada no fluxo migratório, assim como um desequilíbrio acentuado nas relações econômicas e políticas.

É certo que os próprios americanos já tinham dado sinais claros de pouca preocupação com os países latinos, deixando um vácuo geopolítico que vem sendo ocupado, na Venezuela, por Pequim e Moscou, pois, para esses novos aliados, que fizeram grandes investimentos de bilhões de dólares, a presença em um espaço geopolítico historicamente vinculado aos EUA se torna um fator estratégico (inédita escala na Bacia do Atlântico), enquanto o regime 


\section{DA CRISE HUMANITÁRIA EM RAZÃO DO BLOQUEIO ECONÔMICO DOS EUA SOBRE A VENEZUELA DENUNCIADO NA OMC: UMA ANÁLISE A PARTIR DO DIREITO INTERNACIONAL PÚBLICO E DOS DIREITOS HUMANOS}

político na Venezuela, independentemente de qual seja, mantenha e alimente a estabilidade de seus negócios e garanta a estes a preeminência sobre a maior reserva de hidrocarbonetos do mundo.

E apesar do fato recente de que a ONU já tenha se pronunciado favoravelmente ao fim dos embargos e, mesmo que a análise jurídica do sistema de solução de controvérsias da O.M.C leve a entender que possui legitimidade e eficácia para julgar a questão venezuelana sim, pois consiste em um modo jurisdicional de solução de controvérsias, com sanções e outros meios de coação resolutiva. Por outro lado, entende-se também que poucas são as chances de um país como a Venezuela obter algum êxito nesse sistema, pois os americanos possuem um vasto histórico de não se submeterem às decisões dos órgãos julgadores, e não costumam se submeter a quaisquer jurisdições internacionais, cujos atos em relação ao país já podem ser interpretados como atos velados de guerra.

No plano dos direitos humanos, a crise inicia-se com a morte de Hugo Chávez e a eleição de Nicolás Maduro, que, devido ao comportamento autoritário e pouco flexível, contribuiu para a inflação desenfreada no país, que afirma ter sido ocasionada pelos embargos promovidos pelo EUA. A situação foi ficando insustentável, havendo uma escalada da violência, do desemprego, da fome, da saúde, entre outros diversos fatores.

Dando ensejo ao inconformismo social, o desejo de mudança e alternância no poder, que não ocorre devido ao emprego da força e da opressão, tornando o país um campo de guerra entre defensores e opositores da atual situação política do país, situação que se agravou ainda mais com a tentativa de interferência na soberania do país, ou seja, situação gerada pela existência de "dois presidentes no país", originando uma situação complicada, com conflitos armados e insegurança.

Diante desse cenário, o país praticamente parou, e apresenta índices alarmantes de pobreza extrema, inanição, ausência de produtos de higiene, medicamentos, alimentos, e outros produtos necessários que garantem o mínimo existencial.

Tal crise econômica levou à migração dos profissionais de saúde, o que desencadeou a volta de doenças antes erradicadas, como o sarampo, situação que deve ter piorado em decorrência da pandemia da Covid-19, em que vidas devem estar sendo ceifadas sem oportunidade de qualquer combate devido à ausência de comida, remédios e outros insumos que garantem o mínimo para viver. 
Outro aspecto da crise está no movimento migratório que deu origem ao denominado êxodo venezuelano, a migração de venezuelanos para países vizinhos, como Brasil, Peru, Colômbia, Argentina, Bolívia, México, Espanha e Estados Unidos, tornando-se um problema social para tais países, principalmente os latinos.

Ademais, vale destacar, que o principal desafio enfrentado pelos países de acolhida é como administrar esta situação migratória, pois no atual contexto de desaceleração dos países latinos, somados ao déficit fiscal, apresentam grandes problemas sociais em receber essas pessoas. Para piorar ainda mais a situação apresentada, tem-se que adicionar ao cenário a grave situação pandêmica.

Diante dos muitos problemas expostos pela situação humanitária que não só assola a Venezuela, mas também a América Latina, pode-se concluir que a comunidade internacional está ansiosa por resolver os males em que vive o país caribenho, e que sejam flexibilizados os embargos para que o país possa receber alimento, medicamento e produtos de higiene básica, para que essas pessoas consigam ao menos desfrutar de direitos tão básicos e necessários à vida.

Por fim, o que resta é esperar que os países e as organizações internacionais coloquem as questões econômicas e mercadológicas em segundo plano, e que os direitos humanos estejam sempre como prioridade em seus governos e suas ações, para que se possa conseguir alcançar o patamar mínimo civilizatório que garante as premissas de dignidade humana inerente a qualquer pessoa.

\section{REFERÊNCIAS}

ALMEIDA, Silvana Colombo de. Dignidade Humana e Filosofia Hegeliana. Seminário dos estudantes de pós-graduação em filosofia da UFSCar, 10. 2014. Anais [...], p. 374-383, 2014. Disponível em: http://www.ufscar.br/ semppgfil/wp-content/uploads/2012/05/35-SilvanaColombo-de-Almeida.pdf. Acesso em: 10 set. 2021.

BARROSO, Luís Roberto. A dignidade da pessoa humana no direito constitucional contemporâneo: a construção de um conceito jurídico à luz da jurisprudência mundial. Belo Horizonte: Fórum, 2013.

BENEDITO, Flávio. Economia petroleira Venezuelana: o dilema entre a soberania econômica e a dependência estrutural (1973-1998). Tese (Doutorado em História Econômica) - Departamento de História da Faculdade de Filosofia, Letras e Ciências Humanas da Universidade de São Paulo, São Paulo, 2016. Disponível em: 


\section{DA CRISE HUMANITÁRIA EM RAZÃO DO BLOQUEIO ECONÔMICO DOS EUA SOBRE A VENEZUELA DENUNCIADO NA OMC: UMA ANÁLISE A PARTIR DO DIREITO INTERNACIONAL PÚBLICO E DOS DIREITOS HUMANOS}

https://teses.usp.br/teses/disponiveis/8/8137/tde-03032017-113708/pt-br.php. Acesso em: 23 jun. 2021.

BORGES, Vanessa Aguiar. As comunas como estratégia de transição ao socialismo na Venezuela. 2021. Dissertação (Mestrado em Geografia) - Programa de Pós-graduação em Desenvolvimento Territorial na América Latina e Caribe (TerritoriAL), Instituto de Políticas Públicas e Relações Internacionais (IPPRI), Universidade Estadual Paulista "Júlio de Mesquita Filho" (Unesp), Guararema, 2021. Disponível em:

https://repositorio.unesp.br/bitstream/handle/11449/204443/borges_va_me_ippri_int.pdf?sequ ence $=5 \&$ is Allowed=y. Acesso em: 02 out. 2021.

BRANCO, Paulo Gonet; MENDES, Gilmar Ferreira. Curso de Direito Constitucional. 15. ed. São Paulo: Saraiva Educação, 2020.

BRASIL. ANP. Panorama Internacional do Petróleo no Mundo. 2019. Disponível em: http://www.anp.gov.br/ arquivos/central-conteudos/anuario-estatistico/2019/anu0ario-2019texto-secao-1.pdf. Acesso em: 11 jun. 2021.

BRASIL. INEEP. Produção de Petróleo da Venezuela próxima de zero. 2020. Disponível em: https://ineep.org.br/producao-de-petroleo-na-venezuela-proximade zero/\#: :text=A\%20produ\%C3 \%A7\%C3\%A3o\%20venezuelana\%20de\%20petr\% C3\%B3leo,barris\%2C\%20ou\%20muito\%20perto\%20disso. Acesso em: 11 jun. 2021.

CELAG. Centro Estratégico Latinoamericano de Geopolítica. Las Consecuencias Económicas Del Boicot a Venezuela. 08 fev. 2019. Disponível em: https://www.celag.org/las-consecuencias-economicas-del-boicot-venezuela/. Acesso em: 12 jul. 2019.

CORAZZA, Felipe; MESQUITA, Ligia. Crise Na Venezuela: o que levou o país ao colapso econômico e à maior crise de sua história. BBC News, 22 out. 2018. Disponível em: https://www.bbc.com/portuguese/internacional-45909515. Acesso em: 10 set. 2021.

CORPI, Stephania. O êxodo venezuelano que muda a face da América do Sul. El País, Internacional, 14 nov. 2019. Disponível em:

https://brasil.elpais.com/brasil/2019/11/08/internacional/1573170768_919898.html. Acesso em: 10 set. 2021.

CORTEN, Olivier. Méthodologie du Droit International Public. Bruxelas: Editions de 1’Université de Bruxelles, 2009.

CORUGEDO, Emilio Fernández; GUAJARDO, Jaime. Para os vizinhos da Venezuela, a migração em massa traz custos e benefícios econômicos. Diálogo a fondo, 20 nov. 2019. Disponível em: https://www.imf.org/pt/News/Articles/2019/11/21/blog-for-venezuelasneighbors-mass-migration-brings-economic-costs-and-benefits. Acesso em: 12 jul. 2021.

DELGADO, Fernanda; STIER, Klaus; FEBRARO, Júlia; MARQUES, João Victor. Precisamos falar sobre a Venezuela: impactos petropolíticos e reflexos para o Brasil. Caderno Opinião FGV, dez. 2017. Disponível em:

https://fgvenergia.fgv.br/opinioes/precisamos-falar-sobre-venezuela-impactos-petropoliticose-reflexos-para-o-brasil. Acesso em: 20 maio 2021. 
ESPAÑA N., Luis Pedro; PONCE Z., Maria G. Encuesta sobre Condiciones de Vida en Venezuela. Caracas: Universidad Católica Andrés Bello, 2018. Disponível em: https://www.ucab.edu.ve/wp-content/uploads/sites/2/2018/02/ENCOVI-2017presentaci\%C3\%B3n-para-difundir-.pdf. Acesso em: 11 set. 2021.

ESPECIALISTA DA ONU pede para sanções contra Venezuela serem canceladas. ISTO É, 12 fev. 2021. Disponível em: https://istoe.com.br/especialista-da-onu-pede-para-sancoescontra-venezuela-serem-canceladas/. Acesso: 04 jul. 2020.

EUA APREENDEM combustível Iraniano enviado à Venezuela. G1, São Paulo, 14 ago. 2020. Disponível em: https://g1.globo.com/mundo/noticia/2020/08/14/eua-apree ndemcombustivel -iraniano-enviado-a-venezuela.ghtml. Acesso em: 02 jul. 2021.

EUA FATURA mais de US\$ 40 milhões com petróleo confiscado do Irã rumo à Venezuela. ISTO É, São Paulo, 2020. Disponível em: https://istoe.com.br/ eua-fatura-mais-de-us-40milhoes-com-petroleo-confiscado-do-ira-rumo-a-venezuela/. Acesso em: 03 jul. 2021.

FERNANDES, Bernardo Gonçalves. Curso de Direito Constitucional. 12. ed. Salvador: JusPODIVM, 2020.

FERRAJOLI. Luigi. Diritti Fondamentali - Um dibattito teórico. Bari; Roma: Laterza, 2002. (A cura di Ermanno Vitale).

GLOBAL NEWS. Venezuela: falta de alimentos e medicamentos leva 2,3 milhões de pessoas a deixar o País. 15 ago. 2018. Disponível em: https://www.globals.news/pt-

PT_pt/news/2950321/Mundo/Faltadealimentosemedicamentosleva23milh\%C3\%B5esdepesso asadeixaraVenezuela.html. Acesso em: 03 jul. 2021.

HABERMAS, Jürgen. A Inclusão do Outro. Estudos de teoria política. Tradução de George Sperber e Paulo Astor Soethe. São Paulo: Loyola, 2002.

HEGEL, Georg Wilhelm Friedrich. A Razão na História: uma introdução geral à filosofia da história. Tradução de Beatriz Sidou. 2. ed. São Paulo: Centauro, 2001.

HUMAN RIGHTS WATCH. Relatório Mundial 2019: Venezuela. Disponível em: https://www.hrw.org/pt/world-report/2019/country-chapters/326452\#2baede. Acesso em: 11 set. 2021.

KANT, Immanuel. Fundamentação da Metafísica dos Costumes. Tradução de Paulo Quintela. Lisboa: Edições 70, 2007.

MORAES, Alexandre de. Direito Constitucional. 33. ed. São Paulo: Atlas, 2019.

PIOVESAN, Flávia. Direitos humanos e justiça internacional. 2. ed. São Paulo: Saraiva, 2011.

RAMOS, André de Carvalho. Teoria dos Direitos Humanos na Ordem Internacional. 4. ed. São Paulo: Saraiva, 2014.

REGIS, André. Intervenções Humanitárias, soberania e a emergência da Responsabilidade de proteger no Direito Internacional Humanitário. Prim@ Facie, João Pessoa, ano 5, n. 9, p. 517, jul./dez. 2006. Disponível em:

http://www.periodicos.ufpb.br/index.php/primafacie/article/view/7214/4335. Acesso em: 11 set. 2021. 
REZEK, Francisco. Direito Internacional Público - Curso Elementar. São Paulo: Saraiva, 2018.

SEM BLOQUEIO econômico dos EUA, Venezuela não estaria em crise, diz Analista. Rede Brasil Atual, São Paulo, 2 maio 2019. Disponível em:

https://www.redebrasilatual.com.br/mundo/2019/05/sem-bloqueio-economico-dos-euavenezuela-nao-estaria-em-crise-diz-analista/ Acesso: 10 set. 2021.

SINGER, Florantonia. Pobreza extrema beira 80\% na Venezuela. El País, 09 jul. 2020. Disponível em: https://brasil.elpais.com/internacional/2020-07-09/pobreza-extrema-beira-80na-venezuela.html. Acesso em: 12 jul. 2021.

WEISSHEIMER, Marco. Venezuela Enfrenta Criminoso Bloqueio Econômico Dos Estados Unidos Há 15 Anos. Opera Mundi, Diálogos do Sul, Florianópolis, 27 dez. 2019. Disponível em: https://dialogosdosul.operamundi.uol.com.br/economia/62365/venezuela-enfrentacriminoso-bloqueio-economico-dos-estados-unidos-ha-15-anos. Acesso em: 28 jun. 2021.

WOLFFENBÜTTEL, Andréa. O que é? - Índice de Gini. IPEA, Brasília, 1 nov. 2004. Disponível em:

http://www.ipea.gov.br/desafios/index.php?option=com_content\&id=2048: catid=28. Acesso em: 19 jun. 2021. 